greater emphasis should be given in rehabilitation to attempts to alter attitudes and beliefs. Structured supportive counselling, aimed at increasing confidence and reducing fear, may provide a means of considerably reducing disability.

We are grateful to Dr Brenda Rutter for generously providing material for the semantic differential. We thank the staff of the respiratory laboratory, City Hospital Edinburgh, for help with the pulmonary function tests and Mrs M M Jack for typing the manuscript.

\section{References}

1 Office of Health Economics. Preventing bronchitis. London: OHE, 1977.

2 Royal College of Physicians. Disabling chest disease: prevention and care. f $R$ Coll Physicians Lond 1981;15:69-87.

${ }^{3}$ Oswald NC, Walter RE, Drinkwater J. Relationship between breathlessness and anxiety in asthma and bronchitis: a comparative study. $\mathrm{Br}$ Med F 1970;ii:14-7.

4 Rutter BM. Some psychological concomitants of chronic bronchitis. Psychol Med 1978;7:459-65.

${ }^{5}$ Burns BH, Howell JBL. Disproportionately severe breathlessness in chronic bronchitis. $Q \mathcal{F}$ Med 1969;151:277-94.

${ }^{6}$ McGavin CR, Gupta SP, McHardy GJR. Twelve-minute walking test for assessing disability in chronic bronchitis. Br Med f 1976;i:822-3.
${ }^{7}$ McGavin CR, Artvinli M, Naoe H, McHardy GJR. Dyspnoea, disability, and distance walked: comparison of estimates of exercise performance in respiratory disease. $\mathrm{Br}$ Med $\mathcal{F} 1978$;ii:241-3.

${ }^{8}$ Medical Research Council. Classification of chronic bronchitis for clinical and epidemiological purposes. Lancet 1965 ; : $: 775-9$.

${ }^{9}$ Borg G. Perceived exertion as an indicator of somatic stress. Scand $\mathcal{f}$ Rehabil Med 1970;2:92-8.

10 Zuckerman M, Lubin B. Test manual for the multiple affect adjective check list. San Diego: Educational and Industrial Testing Service, 1965.

11 Goldberg DP. Psychiatric disorders. Lancet 1974;ii:775-9.

12 Osgood CE, Suci GJ, Tannenbaum PH. The measurement of meaning. Urbana, Illinois: University of Illinois Press, 1957.

${ }^{13}$ Rutter BM. Prognostic significance of psychological factors in management of chronic bronchitis. Psychol Med 1979;9:63-70.

14 Nie NH, Hull $\mathrm{CH}$, Franklin MN, et al. S.C.S.S.: a user's guide to the SCSS conversational system. New York: McGraw Hill, 1980.

15 Capel LH, Smart J. Obstructive airway disease. Measurement of effort tolerance and forced expiratory volume in bronchitis, emphysema and asthma. Lancet $1959 ; \mathrm{i}: 960-2$.

16 Leitch AG, Hopkin JM, Ellis DA, Merchant S, McHardy GJR. The effect of aerosol ipratropium bromide and salbutamol on exercise tolerance in chronic bronchitis. Thorax 1978;33:711-3.

17 Leitch AG, Morgan AD, Ellis DA, Bell G, Haslett C, McHardy GJR. Effect of oral salbutamol and aminophylline on exercise tolerance in chronic bronchitis. Thorax $1981 ; 36: 787-9$.

(Accepted 25 October 1982)

\title{
Low phospholipid arachidonic acid values in diabetic platelets
}

\author{
D B JONES， R D CARTER，B HAITAS， J I MANN
}

\begin{abstract}
Platelet aggregation is enhanced in diabetes mellitus, and platelets may be implicated in the pathogenesis of diabetic angiopathy. Increased platelet aggregation is probably mediated by the production of the proaggregatory prostaglandin thromboxane, which is synthesised from arachidonic acid (C20:4) by the action of the platelet enzymes cyclo-oxygenase and thromboxane synthetase.

The fatty acid composition of platelet phospholipid was measured in 20 normal controls, 10 insulin-treated diabetics with no or minimal retinopathy, and 10 insulintreated diabetics with proliferative retinopathy. The percentage of arachidonic acid was significantly higher in controls (mean $22.6 \%$ ) than in the diabetics with no or minimal retinopathy (mean $18.5 \% ; p<0.025$ ) and the diabetics with proliferative retinopathy (mean $14.6 \%$; $p<0.001)$. The percentage of linoleic acid was lower in controls (mean $8.9 \%$ ) than in the diabetics with no or minimal retinopathy (mean $12.6 \% ; p<0.01$ ) and diabetics with proliferative retinopathy (mean $13.1 \%$; $p<0.001)$. The mean percentage of linolenic acid was significantly lower in the diabetics with proliferative retinopathy $(2 \cdot 7 \%)$ than in the normal control group $(4.4 \% ; p<0.01)$. A significant negative correlation was found between the percentages of arachidonic acid and
\end{abstract}

Diabetes Research Laboratories and Department of Community Medicine and General Practice, University of Oxford, Radcliffe Infirmary, Oxford OX2 6HE

D B JONES, MRCP, research registrar

R D CARTER, MIST, senior laboratory scientific officer

B HAITAS, MRCP, research registrar

I I MANN, PHD, DM, lecturer in social and community medicine, and honorary consultant physician glycosylated haemoglobin $(\mathrm{Rs}=-0.58 ; \quad$ p $<0.001) . \quad$ A significant positive correlation was found between linoleic acid and the percentage of glycosylated haemoglobin ( $R s=0.51 ; p<0.01)$.

The reciprocal correlation between percentages of arachidonic acid and glycosylated haemoglobin suggests that diabetic control may influence thromboxane release and platelet activity directly and that low percentages of arachidonic acid reflect the increased degree of in-vivo activation.

\section{Introduction}

The control of platelet aggregation is influenced by two conflicting prostaglandins. Thromboxane $A_{2}$ is synthesised and released by platelets and promotes aggregation, ${ }^{1}$ while prostacyclin is produced by vascular endothelium and is antiaggregatory. ${ }^{2}$ Disturbed metabolism of either of these has been suggested as the cause of increased platelet aggregation in diabetes. ${ }^{34}$

Raised circulating concentrations of thromboxane $B_{2}$ (the metabolite of thromboxane $A_{2}$ ) have been shown in diabetics with retinopathy, though thromboxane production by platelets in vitro was low or normal. ${ }^{4}$

We have studied the phospholipid fatty acid composition of platelets from diabetics with minimal background or severe proliferative retinopathy because arachidonic acid represents the crucial substrate for production of thromboxane $A_{2}$. We also studied the relation between glycaemic control and altered composition of platelet fatty acids.

\section{Patients and methods}

We studied three groups of subjects: 20 normal controls, 10 insulin-treated diabetics with no or minimal retinopathy, and 10 
insulin-treated diabetics with proliferative retinopathy. All were men and there were no significant differences in mean age $(45 \cdot 1,45 \cdot 6$, and 45.0 years) and mean percentage ideal body weight $(106 \%, 105 \%$, and $106 \%)$. The two diabetic groups were similar with regard to mean duration of diabetes (24.2 and 25.1 years) and mean insulin dose $/ \mathrm{kg}$ body weight $(0.84$ and 0.79 unit).

The diabetics were originally advised to take a low carbohydrate diet but in practice at the time of the study most were restricting only sugar. The controls received no dietary advice.

The presence and degree of retinopathy was determined by fundoscopy and retinal photography after fluorescein angiography.

Blood was taken after an overnight fast for measurement of glucose concentration, percentage of glycosylated haemoglobin (haemoglobin $A_{1 c}$ ), cholesterol (total and in the lipoprotein fractions), and total triglyceride concentrations. Citrated blood $(30 \mathrm{ml})$ was used to determine phospholipid fatty acid composition. Platelet-rich plasma was prepared by centrifugation at $180 \mathrm{~g}$ for 10 minutes. This was washed twice in $0.9 \%$ sodium chloride and centrifuged at $500 \mathrm{~g}$ after each washing to obtain a platelet pellet. The lipid fraction was extracted using a $2: 1$ chloroform:methanol solvent. Thin-layer chromatography in one dimension using a hexane, diethyl ether, and acetic acid mixture was then performed on an activated silica gel plate to obtain the phospholipid fraction with development in iodine vapour. The phospholipid was then removed and gas-liquid chromatography carried out on methylated aliquots. ${ }^{5}$ The percentage of each fatty acid was then calculated by triangulation from the chromatogram obtained.

Glucose was measured by a glucose oxidase method in a Pye Unican AC1 autoanalyser, haemoglobin $A_{1 c}$ by an isoelectric focusing technique, ${ }^{6}$ cholesterol by a Technicon autoanalyser using the Liebermann-Burchard reaction, and cholesterol lipoproteins after precipitation with heparin-manganese chloride ${ }^{7}$ and sodium dodecyl sulphate. ${ }^{8}$ Serum triglyceride concentration was measured after enzymatic hydrolysis. ${ }^{9}$

The statistical significance of differences was measured by Student's $t$ test and correlations assessed by Spearman's rank correlation coefficient. Analysis of trend was by permutational trend test. ${ }^{10}$

\section{Results}

The fatty acid composition of the platelet phospholipids showed significant differences between normal controls and the diabetic groups for three acids-arachidonic acid, linoleic acid, and linolenic acid. The table shows the mean and standard deviation of the percentages of the three acids and the biochemical variables for the three groups. Five glycosylated haemoglobin and four low density lipoprotein and very low-density lipoprotein samples from the control group were lost in processing. In this group, therefore, these values are expressed as the mean and standard deviation of 15 and 16 results, respectively.

Arachidonic acid (C20:4)-The percentage of arachidonic acid was significantly lower in the diabetic minimal retinopathy group $(18.5 \pm$ $4 \cdot 8 \%)$ than in the normal group $(22 \cdot 6 \pm 3 \cdot 4 \% ; \mathrm{p}<0.025)$ and was also

Percentages of arachidonic acid, linoleic acid, and linolenic acid; percentage of glycosylated haemoglobin; and lipid concentrations in the three groups. (Values are means $\pm S D$

\begin{tabular}{|c|c|c|c|}
\hline & Normal & $\begin{array}{l}\text { Diabetic } \\
\text { (minimal } \\
\text { retinopathy) }\end{array}$ & $\begin{array}{c}\text { Diabetic } \\
\text { (proliferative } \\
\text { retinopathy) }\end{array}$ \\
\hline $\begin{array}{l}\text { Arachidonic acid } \\
\left({ }^{\circ} \text { of total fatty acids }\right)\end{array}$ & $22 \cdot 6 \pm 3 \cdot 4$ & $18.5 \pm 4.8^{*}$ & $14 \cdot 6 \pm 5 \cdot 3^{* * *}$ \\
\hline $\begin{array}{l}\text { Linoleic acid } \\
\text { (") of total fatty acids) } \\
\text { Linolenic acid }\end{array}$ & $8 \cdot 9 \pm 2 \cdot 3$ & $12 \cdot 6 \pm 5 \cdot 0^{* *}$ & $13 \cdot 1 \pm 3 \cdot 5^{* * *}$ \\
\hline $\begin{array}{l}\text { (\% of total fatty acids) } \\
\text { Glucose (mmol/l) } \\
\text { Haemoglobin } \mathrm{A}_{1 \mathrm{c}}(\%) \\
\text { Total cholesterol (mmol/1) }\end{array}$ & $\begin{array}{l}4 \cdot 4 \pm 1 \cdot 2 \\
4 \cdot 8 \pm 0 \cdot 6 \\
7 \cdot 2 \pm 0 \cdot 8 \dagger \\
5 \cdot 0 \pm 0 \cdot 9\end{array}$ & $\begin{array}{l}3 \cdot 4 \pm 1 \cdot 9 \\
11 \cdot 9 \pm 6 \cdot 3^{* *} \\
8 \cdot 7 \pm 1 \cdot 3^{* *} \\
4 \cdot 9 \pm 1 \cdot 1\end{array}$ & $\begin{array}{l}2 \cdot 7 \pm 1 \cdot 7^{* *} \\
10 \cdot 2 \pm 3 \cdot 5^{* * *} \\
11 \cdot 3 \pm 3 \cdot 2^{* * *} \\
4 \cdot 7 \pm 0 \cdot 6\end{array}$ \\
\hline High density lipoprotein & $1.4 \pm 0.3$ & $1 \cdot 5 \pm 0 \cdot 2$ & $1 \cdot 2 \pm 0 \cdot 1$ \\
\hline $\begin{array}{l}\text { Low density lipoprotein } \\
\text { cholesterol (mmol/1) } \\
\text { Very low-density lipoprotein }\end{array}$ & $2 \cdot 9 \pm 0.9 \ddagger$ & $2 \cdot 6 \pm 0 \cdot 7$ & $2.7 \pm 0.5$ \\
\hline $\begin{array}{l}\text { cholesterol }(\mathrm{mmol} / \mathrm{l}) \\
\text { Triglycerides }(\mathrm{mmol} / \mathrm{l})\end{array}$ & $\begin{array}{l}0.7 \pm 0.5 \ddagger \\
1.5 \pm 0.6\end{array}$ & $\begin{array}{l}0.9 \pm 0.7 \\
1.2 \pm 0.5\end{array}$ & $\begin{array}{l}0 \cdot 8 \div 0 \cdot 4 \\
1 \cdot 4 \div 0 \cdot 4\end{array}$ \\
\hline
\end{tabular}

${ }^{*} \mathrm{p}<0.025 ;{ }^{* *} \mathrm{p}<0.01 ;{ }^{* * *} \mathrm{p}<0.001$.

+Mean of 15 samples.

Mean of 16 samples.

Conversion: SI to traditional units-Blood glucose: $1 \mathrm{mmol} / 1 \approx 18 \mathrm{mg} / 100 \mathrm{ml}$
Cholesterol: $1 \mathrm{mmol} / \mathrm{l} \approx 38.6 \mathrm{mg} / 100 \mathrm{ml}$. Triglycerides : $1 \mathrm{mmol} / 1 \approx 88 \mathrm{mg} / 100 \mathrm{ml}$

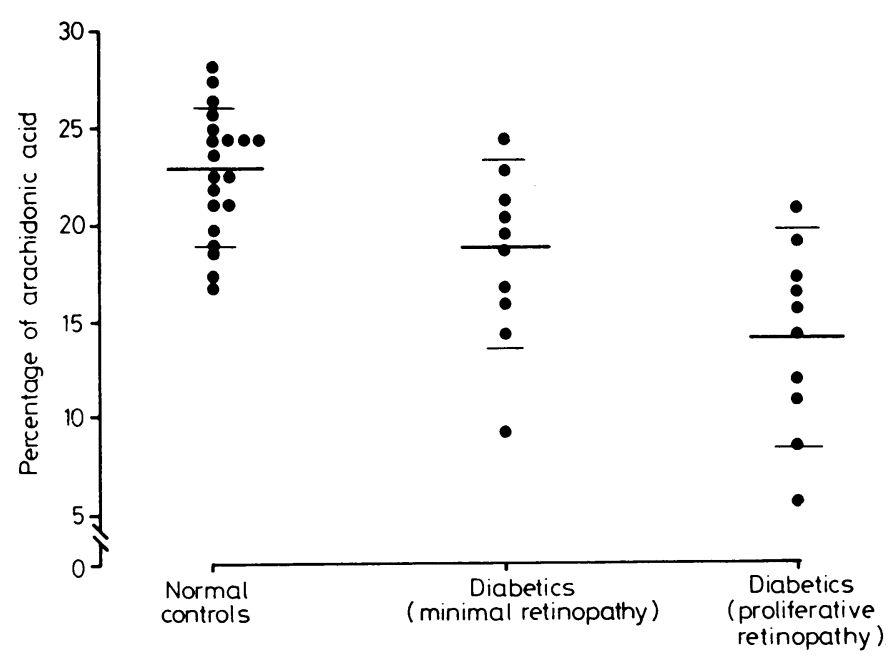

FIG 1-Arachidonic acid percentages of total fatty acids for normal controls, diabetics with no or minimal retinopathy, and diabetics with proliferative retinopathy.

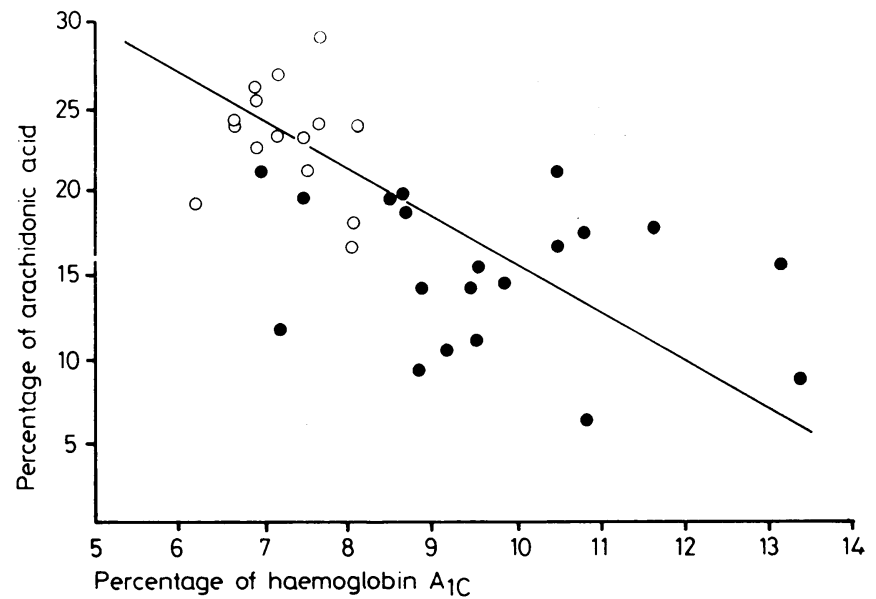

FIG 2-Plot of glycosylated haemoglobin against arachidonic acid for normal controls $(O)$ and diabetics $(\Theta)$.

significantly lower in the diabetic proliferative retinopathy group $(14.6 \pm 5.3 \% ; \mathrm{p}<0.001)$. The difference between the two diabetic groups was not statistically significant $(\mathrm{p}<0 \cdot 1)$ (fig 1 ).

Linoleic acid (C18:2) - The percentage of linoleic acid was higher in both the diabetic proliferative retinopathy group $(13.1 \pm 3.5 \%$; $\mathrm{p}<0.001)$ and the diabetic minimal retinopathy group $(12.6 \pm 5.0 \%$; $\mathrm{p}<0.01)$ than in the controls $(8.9 \pm 2.3 \%)$. The difference between the two diabetic groups was not statistically significant.

Linolenic acid (C18:3) - The percentage of linolenic acid was significantly lower in the proliferative retinopathy group $(2 \cdot 7 \pm 1 \cdot 7 \%)$ than in the normal controls $(4.4 \pm 1.2 \% ; \mathrm{p}<0.01)$.

There was no difference statistically between the three groups for the ratio of arachidonic acid to eicosapentanoic acid (C20:4, C20:5).

The two diabetic groups were similar for all biochemical variables except the percentage of glycosylated haemoglobin, which was higher in the proliferative retinopathy group $(\mathrm{p}<0.025)$.

Correlation of platelet fatty acids and glycaemic control-Significan correlations were present for the percentage of arachidonic acid against the percentage of glycosylated haemoglobin $(\mathrm{Rs}=-0.58$; $\mathrm{p}<0.001$ ) (see fig 2) and also for the percentage of linoleic acid and glycosylated haemoglobin $(\mathrm{Rs}=0.51 ; \mathrm{p}<0.01)$ for the total cohort. When the groups were separated the diabetics showed a significant negative correlation between arachidonic acid and the percentage of glycosylated haemoglobin ( $R s=-0.54 ; \mathrm{p}<0.01)$ but no correlation between linoleic or linolenic acid and glycosylated haemoglobin. In the normal control group no significant correlations were seen between the percentage of glycosylated haemoglobin and arachidonic acid $(R=0 \cdot 14)$ or linoleic acid $(R=0.2)$ but a significant negative correlation was seen with linolenic acid $(R=-0.57 ; p<0.02)$. There were no 
significant correlations present for platelet fatty acid composition and fasting concentrations of plasma glucose or cholesterol, lipoproteins, and total triglycerides.

Trend test-There was no statistically significant trend in either arachidonic acid or linoleic acid according to retinopathy groups.

\section{Discussion}

Abnormal platelet aggregation has been well described in diabetes mellitus, but the mechanism of this disturbed function and its relation to blood glucose control and to diabetic complications are less well understood. ${ }^{11-13}$

We have shown that platelets from diabetics have a lower percentage of arachidonic acid in the phospholipid fraction than platelets of normal subjects. The correlation between the percentage of arachidonic acid and the percentage of glycosylated haemoglobin implies a link between long-term blood glucose control and the biosynthetic pathway of thromboxane in platelets. The fasting blood glucose concentration in normal and diabetic subjects did not correlate with the percentage of arachidonic acid, suggesting that medium and long-term fluctuations in glucose control but not acute changes affect metabolism.

There was no significant difference in percentage of arachidonic acid between the two retinopathy groups, though both differed significantly from normal. The lower mean value in the proliferative retinopathy group was a reflection of poorer glycaemic control in that group. Our results suggest that vascular disease by itself may not influence platelet metabolism.

We could not confirm the report by Kalofoutis and Lekakis ${ }^{14}$ that the percentage of arachidonic acid in diabetic platelets is higher than normal. Their analytical methods were apparently similar to ours and are unlikely to explain the discrepancy. Patient selection, in particular duration of diabetes and body weight, may account for some of the difference but dietary factors were probably more important. Evidence is rapidly accumulating on how diet affects platelet fatty acids. ${ }^{15-17}$ Some dietary regimens may have an adverse effect on platelet behaviour by altering the amount of proaggregatory prostaglandin precursors available for thromboxane synthesis. Experimental support for this hypothesis includes the reduction of platelet aggregation by supplementation with eicosapentanoic acid $^{18}$ in normal subjects and also data from studies in Eskimos, ${ }^{19}$ which show changes in platelet structure and aggregation related to high polyunsaturated fat intake. Differences may exist in the kinetics of the arachidonic pathway between populations.

Linoleic acid may play an indirect part in the balance of platelet aggregation. Studies have shown reduced platelet aggregation in subjects fed linoleic acid supplements ${ }^{20}$ and increased platelet aggregation in subjects fed arachidonic acid. ${ }^{16}$ Arachidonic acid occurs in only small amounts in food and it has long been thought that conversion from linoleic acid takes place. Our results show that diabetics have more linoleic acid in their platelets than normal subjects, which contrasts with the increased platelet aggregation seen in diabetics. Possibly diabetics have an inability to convert linoleic acid to arachidonic acid which in some way contributes to the platelet instability and which correlates with glycaemic control. The percentage of linolenic acid was significantly lower in the diabetics with proliferative retinopathy than in the normal controls but no difference occurred between the minimal retinopathy group and the controls. Linolenic acid undergoes conversion to eicosapentanoic acid and subsequently to analogues of thromboxane which show reduced biological activity. The low percentages of linolenic acid may further contribute to imbalance in an equilibrium of thromboxane analogues. The proportion of eicosapentanoic acid itself, however, was not significantly different among the three groups.

Other workers have suggested that the ratio of arachidonic acid to eicosapentanoic acid is important in platelet aggregation $^{1718}$ but we observed no differences in this ratio between our normal controls and the two diabetic groups.
We believe that our results help to explain previous data on thromboxane production in diabetes. Though circulating concentrations of thromboxane $B_{2}$ are raised in diabetes, in-vitro thromboxane production by platelets is reduced. ${ }^{4}$ When arachidonic acid is added to platelets in low concentrations thromboxane production is increased. ${ }^{21}$ Both these findings are compatible with reduced amounts of endogenous platelet arachidonic acid.

We should expect an increase in platelet arachidonic acid coupled with a decrease in platelet aggregation after any therapeutic measure which improved glycaemic control in diabetes.

We have shown a correlation between glycaemic control and altered composition of platelet fatty acids and postulate that glycaemic control directly influences prostaglandin metabolism in diabetes mellitus.

We are grateful to Karen Barker and Richard Jelfs for technical work and to Dr T M E Davis for practical advice and help. We thank the Simon Broome Heart Research Trust for financial support, and Mrs Anne Reeve for typing the manuscript.

\section{References}

${ }^{1}$ Kloeze J. Influence of prostaglandins on platelet adhesiveness and platele aggregation. In: Bergstrom S, Samuelsson B, eds. Prostaglandins: proceedings of 2nd Nobel symposium. New York: Interscience, 1967 241-50.

Moncada S, Higgs GA, Vane SR. Human arterial and venous tissues generate prostacyclin (PGx), a potent inhibitor of platelet aggregation Lancet $1977 ; \mathrm{i}: 18-20$.

${ }^{3}$ Silberkane K, Schernthauer G, Sinziger $H$, Pizakalzer $H$, Winter $M$ Decreased vascular prostacyclin in juvenile-onset diabetes. $N$ Englf $\mathrm{Med}$ $1979 ; 300: 366-7$

4 Ylikorkala O, Kaila J, Viinikka L. Prostacyclin and thromboxane in diabetes. Br Med 7 1981;283:1148-50.

${ }^{5}$ Dodge JT, Phillips GB. Composition of phospholipids and phospholipid fatty acids and aldehydes in human red cells. $\mathcal{F}$ Lipid Res 1967;8:667-75.

${ }^{6}$ Jeppsson JO, Franze B, Gaal AB. Simplified determination of haemoglobin $\mathrm{A}_{1 \mathrm{c}}$ in diabetic patients by use of electrofocusing. In: Radola BS, ed. Electrophoresis 1979. Advanced methods: biochemical and clinical applications. Berlin: Walter de Gruyter and Co, 1980.

7 Burstein M, Scholnick HR, Morfin R. Rapid method for the isolation of lipoproteins from human serum: precipitation with polyanions. $\mathcal{F}$ Lipid Res 1970;11:583-95.

${ }^{8}$ Ononogba IC, Lewis B. Lipoprotein fraction by a precipitation method: a simple quantitative procedure. Clin Chem Acta 1976;71:397-402.

9 Wahlefeld AW. Triglycerides: determination after enzymatic hydrolysis In: Bergmeyer HU, ed. Methods of enzymatic analysis. 2nd Eng ed. New York and London: Academic Press Inc, 1974:1831.

10 Dornan T, Mann JI, Turner R. Factors protective against retinopathy in insulin dependent diabetics free of retinopathy for 30 years. $\mathrm{Br} \mathrm{Med} \mathcal{J}$ $1982 ; 285$ :1073-7.

11 Szirtes M. Platelet aggregation in diabetes mellitus. Adv Cardiol 1970;4: 179-86.

12 Juhan I, Buonocore $M$, Jouve $R$, Vague P, Monlin JP, Vialettes B Abnormalities of erythrocyte deformability and platelet aggregation in insulin dependent diabetics corrected by insulin in vivo and in vitro. Lancet 1982; :535-9.

13 Sagel J, Colwell JA, Crook L, Laimins M. Increased platelet aggregation in early diabetes mellitus. Ann Intern Med 1975;82:733-8.

${ }^{14}$ Kalofoutis A, Lekakis J. Changes of platelet phospholipids in diabetes mellitus. Diabetologia 1981 ;21:540-3.

${ }^{15}$ Renaud S, Morazain R, Godsey F, et al. Platelet function in relation to diet and serum lipids in British farmers. Br Heart 7 1981;46:562-70.

${ }^{16}$ Seyberth HW, Oelz O, Kennedy $\mathrm{T}$, et al. Increased arachidonate in lipids after administration to man: effects on prostaglandin biosynthesis. Clin Pharmacol Ther 1975;18:521-9.

17 Seiss W, Scherer B, Bohlig B, Roth P, Kurzmann I, Weker PC. Platelet membrane fatty acids, platelet aggregation and thromboxane formation during a mackerel diet. Lancet 1980;i:441-4.

18 Thorngren M, Gustafson A. Effects of 11 week increase in dietary eicosapentanoic acid on bleeding time, lipids and platelet aggregation. Lancet $1981 ; \mathrm{ii}: 1190-3$.

19 Dyerberg J, Bang HO. Haemostatic function and platelet polyunsaturated fatty acids in Eskimos. Lancet 1979 ;ii:433-5.

${ }^{20}$ Fleischman AI, Bierenbaum ML, Justice D, Stier A, Sullivan A, Fleischman $M$. Titrating dietary linoleate to in vivo platelet function in man Am 7 Clin Nutr 1975;28:601-5.

21 Jackson CA, Boulton AJM, Ward JD, Preston FG. Abnormalities of platelet prostaglandin biosynthesis in diabetic neuropathy. Diabetologia $1981 ; 2: 508$.

(Accepted 26 October 1982) 